\title{
Dossiê - “Novas classes médias": famílias em mudança?
}

\author{
Belinda Mandelbaum \\ Universidade de São Paulo, Instituto de Psicologia, Laboratório de Estudos da Família, \\ Relação de Gênero e Sexualidade (LEFAM). São Paulo, SP, Brasil
}

O conjunto de artigos aqui reunidos é resultado das exposições e debates que compuseram o seminário "Novas classes médias": famílias em mudança?, organizado em agosto de 2013 pelos pesquisadores do Laboratório de Estudos da Família, Relações de Gênero e Sexualidade (LEFAM) do Departamento de Psicologia Social e do Trabalho, no IPUSP. O seminário teve origem nas indagações mobilizadas pelas pesquisas com famílias em diversas situações de vulnerabilidade social, e com as políticas públicas voltadas para elas, em especial no campo da Saúde e da Assistência Social. A publicação destes artigos, decorrido mais de um ano do seminário, não apenas registra a rica diversidade de perspectivas a partir das quais o fenômeno das "novas classes médias" foi examinado na ocasião por estudiosos das Ciências Políticas, da Economia, da Antropologia, da Cultura, da Religião e da Psicologia Social, mas traz significativas contribuições para compreendermos a sociedade brasileira hoje, ainda que o quadro econômico e político já não seja o mesmo.

Tanto as mídias como o mundo acadêmico trataram, com ênfase recente nos governos Lula e Dilma Rousseff, do fenômeno de ascensão social de milhões de famílias brasileiras, que ocorreu de formas diversas ao longo dos estratos que compõem a nossa sociedade, desde a saída da miséria absoluta através do Bolsa Família até o ingresso de uma parcela menor de pobres no universo de trabalho e consumo das classes médias tradicionais. De uma parte importante de famílias antes consideradas pertencentes às chamadas classes $\mathrm{D}$ e $\mathrm{E}$, diz-se que ascenderam neste período ao que se denominou de "novas classes médias". $\mathrm{O}$ que isto quer dizer? E o que significou na vida dessas pessoas? Que mudanças, de fato, ocorreram? O que é, de fato, novo? É consenso entre os estudiosos situar o novo na ascensão de aproximadamente 40 milhões de brasileiros ao mercado de consumo. Dizer isto de qualquer ponto de vista, e em nosso caso como psicólogos sociais, já é dizer muito. Pois o consumo é de casas (de novas formas de morar), de carros (portanto ganho em mobilidade, viagens, novas paisagens), de modas (novas formas de vestir), o que evidentemente impacta o corpo, a sexualidade e o desejo. Mas é consenso também que a desigualdade social no Brasil resiste fortemente à mudança e que indicadores fundamentais de desenvolvimento, como saúde e edu- cação, permanecem em níveis insatisfatórios, precários, o que perpetua condições de vulnerabilidade. Há, então, verdadeira novidade no campo social, ou trata-se apenas, literalmente, de roupas novas para as velhas formas da desigualdade? O diálogo entre as perspectivas presentes neste dossiê compõem um quadro multifacetado desse fenômeno social, do qual exponho aqui alguns traços.

O cientista político André Singer, em "Quatro notas sobre as classes sociais nos dez anos do lulismo", coloca em questão o termo "novas classes médias", ao sugerir que se trata, na verdade, de um novo proletariado que viria migrando, nesses anos, do subproletariado para uma cidadania de direitos trabalhistas assegurados pela carteira de trabalho assinada. Neste sentido, estaria sim havendo um combate à desigualdade em nosso país, mas lento, tendo se iniciado em patamares de intensa precariedade das condições de vida de grande parcela da população. Outro aspecto característico do modo como os governos de Lula e Dilma têm enfrentado esse combate à miséria e à desigualdade é a composição com o capital, evitando assim a luta de classes. Mas o autor evidencia também a precariedade do processo: pode haver uma reconversão do novo proletariado à condição subproletária se houver desemprego, em tempos de crise econômica, tais como a que se deflagra no atualmente. Não é à toa que Braga (2013), citado aqui por Singer, prefere chamar essas "novas" classes sociais de precariado.

Ladislau Dowbor, em "A economia da família", aborda essa precariedade principalmente a partir das transformações ocorridas na economia das famílias que, se por um lado tiveram ampliados o acesso ao emprego e ao estudo universitário, por outro estão escravizadas ao crediário, que consome em média $35 \%$ da renda dos pobres. $\mathrm{O}$ autor agrega à análise deste estado de coisas a crescente atomização das famílias contemporâneas - nas quais se desfazem os vínculos de solidariedade que asseguravam a sobrevivência de crianças e idosos -, a fragilização do Estado e a privatização dos serviços sociais, que não dão conta de garantir a manutenção dos cuidados necessários às diferentes gerações, com impactos preocupantes nas dinâmicas da reprodução social. Em suas palavras, "no conjunto, portanto, enquanto as fases não remuneradas de nossas vidas se expandem e a família perde o seu papel redistribuidor, 
as comunidades perdem o seu caráter de solidariedade, o Estado ainda engatinha no seu papel de provedor e o setor privado abocanha os recursos e os direciona para as elites, agravando a situação do conjunto" (p. 16). O texto de Ladislau, que é economista, enfatiza suas preocupações como humanista: "Que vida familiar podemos esperar de quem vive na periferia, levanta às 5 da manhã, volta às 8 da noite e adormece no sofá em frente a um programa suficientemente idiota para adormecê-lo?" (p. 20). Fica evidente nessa imagem a exaustão, a dificuldade dos deslocamentos pela cidade, a falta do convívio familiar e a solidão.

A audiência da televisão está no foco das atenções do artigo da antropóloga Heloisa Buarque de Almeida, “"Classe média' para a indústria cultural", que reflete sobre a noção de classe social, mais especificamente de classe média, no meio publicitário e de marketing a partir de entrevistas que realizou com profissionais da área. Seus achados ajudam a compreender como a TV é responsável por uma "educação para o consumo" que é formadora de um mercado consumidor nacional ou, segundo as suas palavras, de um mercado-nação no interior do qual o que se propagou como "novas classes médias" representa apenas a ampliação do consumo de bens industrializados por um público espectador visto preponderantemente como consumidor. A família, nesta visão, é compreendida como núcleo de consumo, e sua destinação às compras explica 0 alto endividamento apontado no artigo de Dowbor. A autora explicita que tal destinação não garante a essas famílias o acesso a serviços como saúde e educação de qualidade, assegurados às classes médias tradicionais. A partir das reflexões que o artigo engendra, fica evidente que a forma de nomear as classes sociais varia de acordo com os interesses de quem as formula: neste caso a indústria cultural, mas em outros as forças político-partidárias, que dependendo de seus posicionamentos no espectro ideológico e nas demandas eleitoreiras, enfatizam o crescimento das "novas classes médias", por um lado, ou denunciam o fenômeno como produção de marketing, como fazem alguns setores mais à esquerda. Daí a importância, como diz a autora, de buscar entender o que está de fato sendo nomeado em cada caso.

Ricardo Teperman, em "O rap radical e a 'nova classe média", propõe que o aumento do poder de consumo e a "democratização do acesso à tecnologia e à educação" produziram mudanças significativas não apenas nos temas das novas gerações do rap, mas nas suas formas de vinculação com a indústria cultural. A primeira geração assumiu um posicionamento forte na luta de classes, denunciando em suas letras - e também na recusa em participar do mercado artístico hegemônico - a desigualdade, a humilhação, o racismo, a violência policial e "outras mazelas da sociedade brasileira”. Já em 2012, em entrevista para a revista Rap Nacional, Mano Brown, que embora seja da primeira geração, é possível acompanhar o impacto das transformações recentes em sua carreira, diz: "o Brasil vive um momento novo e nós temos que saber atuar em cima desse momento. Está sobrando um pouco mais de dinheiro, a informação está chegando mais rápido" (p. 39). Uma evidência da novidade é o rap ostentação, que passa a veicular a valorização do acesso ao consumo de marcas, passando agora, junto com os governos petistas de Lula e Dilma, por cima do antagonismo entre as classes e contribuindo para sua harmonização e conciliação. De maneira geral, as várias vertentes do rap demonstram hoje uma "relação descomplicada com a ideia de mercado, com a autopromoção e com a grande mídia" (p. 40). Desta forma, conclui o autor, "o enfraquecimento do rap como fenômeno de classe é inversamente proporcional ao seu fortalecimento como gênero musical de mercado" (p. 41). O rap evidencia, assim, em música, a mudança de valores que acompanhou a ascensão social de uma parcela da população brasileira pobre.

Em "Prosperidade sim, família homossexual, não! A nova classe média evangélica", Jung Mo Sung, estudioso do campo da religião e da teologia, discute as relações entre a Teologia da Prosperidade - uma linha da Igreja Evangélica que promete, pela obediência à Vontade Divina, a integração e ascensão social no interior da classificação social capitalista - e o "conservadorismo" moral e familiar que caracteriza uma parcela significativa da "nova classe média" brasileira, expresso no modo militante e por vezes agressivo com que, segundo o autor, esses setores da sociedade se opõem a formas alternativas de conceber a família e a sexualidade. Sua hipótese é que, se por um lado a Teologia da Prosperidade promete a participação na sociedade de consumo, por outro sua militância vigilante da moral sexual e familiar garante a diferenciação dos crentes em relação às perdições do mundo. Neste sentido, é interessante notar como as observações do autor no campo da sociologia da religião dialogam com aquelas de Ricardo Teperman no campo da produção musical, de Heloisa B. de Almeida quanto à audiência de TV e marketing, com as de Ladislau Dowbor ao tratar da economia das famílias e André Singer, em suas notas sobre as classes sociais no Brasil durante o lulismo, para tecer o panorama de produção de uma "nova" classe social que se espelha nas classes médias tradicionais, é moral e politicamente conservadora e, direcionada para o consumo, oferece seus sacrifícios aos deuses do mercado capitalista.

Para o campo da Psicologia Social, importa indagarmo-nos, a partir dessas configurações, sobre todas essas sociologias na psique, ou seja, sobre os sentidos e impactos psíquicos de mudanças sociais que, sejam lá o que forem, produzem seus efeitos. Com Freud aprendemos que os sonhos são feitos da materialidade do cotidiano, dos restos diurnos. São os elementos do cotidiano que se engancham nas histórias infantis e as mobilizam. Que demandas essas novas condições de realidade e este novo imaginário social fazem ao psiquismo? Que anseios se realizam, que novas necessidades e desejos geram? E se consideramos especificamente as relações familiares, que novas demandas mobilizam, por exemplo, nas relações do casal ou entre pais e filhos, ou entre novos vizinhos em novas casas? Algumas dessas questões impuseram-se ao grupo de pesquisadores do LEFAM - Luís Fernando Saraiva, Joyce Cristina 
Rezende, João Victor de Souza Reis, Márcio Dionízio Inácio e Lia Vainer Schucman - que, após o seminário, escreveram em conjunto o artigo que fecha este dossiê, "'A nova classe média': repercussões psicossociais em famílias brasileiras", no qual analisam efeitos psicossociais na constituição de modos de subjetivação e em famílias a partir das mudanças sociais em foco. Como tais efeitos, apontam a construção de certo "estilo de vida" marcado pela tentativa de planejamento do futuro, pelo consumo e pela meritocracia, que aproxima os setores da população incluídos no rótulo de "nova classe média" das classes médias tradicionais, tanto em muitos de seus valores como no comportamento político que, "associado ao vínculo com certos setores religiosos e a um crescente individualismo, vem se mostrando mais à direita, a favor de um discurso de corte de impostos para poder usufruir o que conquistou pelo trabalho" (p. 53). Esta fruição se dá através de um consumo sempre insaciável de bens materiais, capaz de produzir, ainda que fugazmente, a sensação de inclusão e potência, uma vez que atribui status, valor e prestígio a quem os adquire. $\mathrm{O}$ artigo aponta ainda, como efeitos dessa configuração social, o individualismo, a competitividade, a redução da teia de solidariedades, a diferenciação e discriminação entre pessoas de mesma origem, a culpabilização e psicologização da vida social, cujas explicações são reduzidas aos desempenhos individuais. Segundo Estanque (2013), as políticas lulistas teriam conseguido instigar no imaginário popular uma espécie de "utopia brasileira" fundada no consumismo e no individualismo.

Hoje, setembro de 2014, o cenário mudou: a economia brasileira mostra resultados ruins e sintomas de recessão ${ }^{1}$, com projetos para o futuro abandonados ou adiados e o comércio em queda. Para muitas famílias, isso significa cortes no consumo, redução de contas e insegurança em relação ao emprego ${ }^{2}$. O que era novo, a "nova classe média", depois de uma década, acabou? Experimentou o gosto da roupa nova, da viagem de avião e agora, como diz a exsecretária na mesma reportagem, "não vou ficar com um bife de terceira". O cenário agora se abre para o exame do impacto das perdas e frustrações que mais uma vez tendem a se avolumar para pessoas que puderam, por um tempo, provar do gosto de satisfazer seus "sonhos de consumo" e ostentar suas realizações. Esse exame, entretanto, é assunto para outra ocasião.

1 Economia do país encolhe $0,6 \%$ no $2^{\circ}$ trimestre e indica recessão. Folha de São Paulo, 30/08/2014.

2 Secretária perde vaga e reduz gastos para economizar. Folha de São Paulo, 31/08/2014. Interessante que, no mesmo Caderno Mercado, duas páginas depois, lê-se o título de outra matéria: Extrovertidos e meticulosos ganham mais, diz estudo. Ou seja, diante da crise e da insegurança frente à perda do emprego, novamente a Psicologia é acionada para justificar o destino profissional de cada um. 